\title{
Beta2-glycoprotein I cooperate with hepatitis B surface antigen promotes hepatocellular carcinogenesis via the nuclear factor kappa B signal pathway were enhanced by the lipopolysaccharide
}

\author{
Xue-Li Ding ${ }^{1 *}$, Xue Jing1*, Nai-Jun Han², Zi-Bin Tian'1, Pu-Jun Gao³, Lin Yang1, Ya-Nan Yu \\ 1Department of Gastroenterology, the Affiliated Hospital of Qingdao University, Qingdao 266003, Shandong, China. \\ 2Department of Research and development, Yebio Bioengineering Co., Ltd. of Qingdao, Qingdao 266114, Shandong, China. \\ ${ }^{3}$ Department of Hepatology, the First Hospital of Jilin University, Changchun 310021, Jilin, China. \\ ${ }^{\star}$ Authors contributed equally
}

Correspondence to: Dr. Xue Jing, Department of Gastroenterology, the Affiliated Hospital of Qingdao University, No.16 Jiangsu Road, Qingdao 266003, Shandong, China. E-mail: qdu-jingxue@foxmail.com

How to cite this article: Ding XL, Jing X, Han NJ, Tian ZB, Gao PH, Yang L, Yu YN. Beta2-glycoprotein I cooperate with hepatitis B surface antigen promotes hepatocellular carcinogenesis via the nuclear factor kappa B signal pathway were enhanced by the lipopolysaccharide. Hepatoma Res 2018;4:12. http://dx.doi.org/10.20517/2394-5079.2018.07

Received: 11 Feb 2018 First Decision: 8 Mar 2018 Revised: 30 Mar 2018 Accepted: 2 Apr 2018 Published: 28 Apr 2018

Science Editor: Guang-Wen Cao Copy Editor: Guang-Zhe Zhu Production Editor: Huan-Liang Wu

\begin{abstract}
Aim: We aimed to elucidate whether beta2-glycoprotein I ( $\beta 2 \mathrm{GPI})$ cooperation with hepatitis B surface antigen ( $\mathrm{HBsAg}$ ) promoted hepatocellular carcinogenesis enhanced by the lipopolysaccharide (LPS) via activation of nuclear factor kappa B (NF- $\mathrm{KB}$ ) and expression of tumor necrosis factor- $\alpha$ (TNF- $\alpha$ ), interleukin-1 $\beta$ (IL-1 $\beta$ ), and alpha fetal protein (AFP) in liver cancer cells.
\end{abstract}

Methods: Liver cancer cells (SMMC-7721) were transiently transfected with $\beta 2 \mathrm{GPI}$ and/or HBsAg and were subjected to LPS treatment. TNF- $\alpha$, IL-1 $\beta$, and AFP expression were measured in all groups by ELISA. NF- $\kappa B$ activation was assessed by non-radioactive electrophoretic mobility shift assay (EMSA) and was quantified in all groups.

Results: Cells transfected with $\beta 2 \mathrm{GPI}$ and/or $\mathrm{HBsAg}$ induced activation of $\mathrm{NF}-\kappa \mathrm{B}$, with the highest activation seen in the doubly $\beta 2 \mathrm{GPI}$ - and HBsAg-transfected cells treated with LPS. Non-transfected cells treated with LPS exhibited lower activation compared to either $\beta 2 \mathrm{GPI}$ - or HBsAg-transfected cells with LPS treatment. In addition, cells transfected with $\beta 2 \mathrm{GPI}$ and/or HBsAg induced significantly increased expression of TNF- $\alpha$, IL-1 $\beta$ and AFP, with the highest levels again seen in the doubly $\beta 2 \mathrm{GPI}$ - and HBsAg-transfected cells treated with LPS.

Conclusion: These observations suggest that the activity of NF- $\mathrm{kB}$ induced by $\beta 2 \mathrm{GPI}$ and $\mathrm{HBs} A g$ was enhanced by LPS. Expression of TNF- $\alpha$, IL-1 $\beta$ and AFP increased in $\beta 2$ GPI and HBsAg cotransfected liver cancer cells.

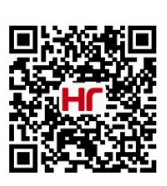


Keywords: Beta2-glycoproten I, hepatitis B surface antigen, lipopolysaccharide, liver cancer SMMC-7721, nuclear factor kappa B

\section{INTRODUCTION}

Beta2-glycoprotein I ( $\left.\beta_{2} \mathrm{GPI}\right)$ also known as apolipoprotein $\mathrm{H}(\mathrm{apoH})$, is an abundant glycoprotein in the plasma ${ }^{[1]}$. To date, most studies of $\beta 2$ GPI have focused on its role in anti-phospholipid antibody-thrombosis syndrome $^{[2,3]}$, lipid metabolism, coagulation, and/or regulation of the fibrinolysis system ${ }^{[4]}$. Mehdi et al..$^{[5]}$ found hepatitis B surface antigen ( $\mathrm{HBsAg}$ ) bound $\beta_{2} \mathrm{GPI}$, an interaction that has been of interest to our research group. We previously found that there was a substantially increased level of $\beta 2$ GPI in hepatitis B-related hepatocellular carcinoma (HCC) tissue ${ }^{[6]}$. The combination of $\beta 2$ GPI and HBsAg substantially activated nuclear factor kappa $\mathrm{B}(\mathrm{NF}-\kappa \mathrm{B})^{[6]}$, suggesting that $\beta 2 \mathrm{GPI}$ played a role in the pathogenesis of hepatitis B-related HCC.

A recent study ${ }^{[7]}$ showed that lipopolysaccharide (LPS) specifically interacted with $\beta_{2}$ GPI, activating NF- $\kappa \mathrm{B}$ via toll-like receptor 4 (TLR4) signaling pathway in macrophages. NF- $\kappa B$ is a pleiotropic transcription factor involved in inflammation-associated tumor promotion and progression in $\mathrm{HCC}^{[8]}$. Most hepatitis B-related liver cancer patients experience dysbacteriosis, resulting in increased levels of and sensitivity to LPS. In the present study, we further examined whether LPS enhanced the effect of $\beta_{2}$ GPI and HBsAg on activation of $\mathrm{NF}-\mathrm{\kappa B}$, as well as the expression of cytokine factors in the liver cancer cells.

\section{METHODS}

\section{Experimental groups}

The human hepatoma cell line SMMC-7721 maintained in our laboratory were gifts from the central laboratory of the First Affiliated Hospital of Jilin University. The cells were incubated with Iscove's modified Dulbecco's medium (IMDM) culture media purchased from Gibco, containing 10\% fetal bovine serum (FBS), and maintained at $37{ }^{\circ} \mathrm{C}$ in a $5 \% \mathrm{CO}_{2}$ incubator. All cells were grown to adherence and were passaged every 2-3 days. Cells in the logarithmic growth phase were selected for experimental use. SMMC-7721 cells were divided into six experimental groups. Group A was the control group, neither transfected nor treated; group $B$ was co-transfected with $\beta_{2}$ GPI- and HBsAg plasmids without LPS treatment; group C was treated with $500 \mu \mathrm{L}(100 \mathrm{ng} / \mathrm{mL})$ LPS and incubated for $6 \mathrm{~h}^{[9]}$; group D was transiently cotransfected with $\beta 2 \mathrm{GPI}$ and HBsAg plasmids after treatment with $500 \mu \mathrm{L}(100 \mathrm{ng} / \mathrm{mL})$ LPS and incubated for $6 \mathrm{~h}$; group E was transiently $\beta 2$ GPI-transfected after treatment with $500 \mu \mathrm{L}(100 \mathrm{ng} / \mathrm{mL})$ LPS and incubated for $6 \mathrm{~h}$; group F was transiently HBsAg-transfected after treatment with $500 \mu \mathrm{L}(100 \mathrm{ng} / \mathrm{mL}) \mathrm{LPS}$ and incubated for $6 \mathrm{~h}$.

\section{Cell transfection}

Groups B, D, E, and F were respectively transfected. The vector pcDNA3.1(-) was obtained from Invitrogen. The pcDNA3.1(-)-beta2-GPI and pcDNA3.1(-)-HBsAg eukaryotic expression plasmids were constructed previously in our laboratory. The recombinant plasmids, pcDNA3.1(-)- $\beta 2$ GPI, or pcDNA3.1(-)HBsAg at $1 \mu \mathrm{g} /$ well, and both at $3 \mu \mathrm{g} /$ well $(1: 3)$ were dissolved in $50 \mu \mathrm{L}$ IMMD basal media that was mixed to become Solution A. $2 \mu \mathrm{L}$ FuGENE HD transfection reagent was dissolved in $50 \mu \mathrm{L}$ IMMD basal media, mixed gently, incubated at room temperature for $5 \mathrm{~min}$, labeled as Solution B. Solution A and Solution B were mixed gently to become Solution C, incubated at room temperature for $20 \mathrm{~min}$. The cells were washed 3 times in serum-free IMMD culture media, and Solution C was slowly added to the cells that were incubated at $37{ }^{\circ} \mathrm{C}$ in a $5 \% \mathrm{CO}_{2}$ incubator. Transfection media was removed after $6-8 \mathrm{~h}$ and was replaced with $500 \mu \mathrm{L} 10 \%$ FBS IMDM media. Cell supernatants were collected at $24 \mathrm{~h}$ after transfection. A previous study ${ }^{[6]}$ from our lab found $\beta_{2}$ GPI protein expression was the highest $24 \mathrm{~h}$ after transfection. 


\section{Enzyme-linked immunosorbent assay analysis}

Enzyme-linked immunosorbent assay (ELISA) detection of targets of interest was performed according to the manufacturers' instructions. $\beta_{2} \mathrm{GPI}$ was measured in groups $\mathrm{A}, \mathrm{B}, \mathrm{D}$, and E; HBsAg in groups $\mathrm{B}, \mathrm{D}$ and F; and tumor necrosis factor- $\alpha$ (TNF- $\alpha$ ), interleukin- $1 \beta$ (IL- $1 \beta$ ), and alpha fetal protein (AFP) in all groups. Once $\beta 2$ GPI reached the highest expression level, as determined from previous studies ${ }^{[6]}$, cell supernatants from each group were collected for ELISA analysis. Triplicates of standards, samples and blank groups were prepared. The optical density (OD) value of each well was measured at $450 \mathrm{~nm}$. Data were presented as means $\pm \mathrm{SD}$.

\section{Non-radioactive NF-KB EMSA and NF-KB relative quantification}

Assays were performed only with nuclear extracts according to the manufacturer's instructions. Nuclear extracts $(5 \mu \mathrm{g})$ were used for each reaction with 400 fmol bio-labeled (hot) oligonucleotide NF- $\kappa$ B probe (5'-AGT TGA GGG GAC TTT CCC AGGC-3') and unlabeled (cold)-NF- $\kappa$ B probe (5'-AGT TGA GGG GAC TTT CCC AGGC-3'). Poly(dI-dC): poly(dI-dC) was used as a nonspecific competitor. A 25 -fold molar excess of unlabeled homologous oligonucleotide was used as a specific competitor. Non-homologous oligonucleotide sequences were also used to validate the specificity of the binding of each transcription factor in the competition assays. Binding reaction resolved by $6.5 \%$ acrylamide/bis (30:1 ratio) electrophoresis in $0.25 \times \mathrm{TBE}$ on ice. The gel was transferred to nitrocellulose membranes in $0.5 \times$ TBE. The membrane was then UV crosslinked for $10 \mathrm{~min}$, blocked with $1 \times$ blocking buffer for $30 \mathrm{~min}$, and then incubated with streptavidin-HRP in blocking buffer (1:750) at room temperature for $30 \mathrm{~min}$. The membrane was washed four times with $1 \times$ washing solution and was equilibrated with $1 \times$ equilibration solution for 5 min with shaking. Finally, the membranes were incubated with chemiluminescence substrate buffer, and the bands were visualized using Viagene CoolImager (Viagene Biotech Co., China). NF- $\mathrm{B}$ relative quantification was based on relative activity of the combination of NF- $\kappa B$ and DNA. The last result was represented by $\Delta \Phi$ (gray value). The gray values of the image were measured after film exposure by the imaging system CoolImger. Data were presented as means \pm SD.

\section{Statistical analysis}

SPSS 22.0 software was used for data processing and statistical analysis. Cell assay data were presented as means \pm SDs and the variance was analyzed. Comparison between groups was measured using Fisher's least significant difference (LSD) test. Differences were significant at $P<0.05$.

\section{RESULTS}

\section{Expression of $\beta 2 \mathrm{GPI}$ and HBsAg in transfected cells}

We used ELISA to measure expression of $\beta 2 \mathrm{GPI}$ and HBsAg $24 \mathrm{~h}$ after transfection of recombinant plasmids in cell supernatants. $\beta 2$ GPI protein expression was found in group $B, D$, and $\mathrm{E}$, significantly different from non-transfected, non-treated group A $(P<0.001)$. There were no differences in expression levels of $\beta 2 \mathrm{GPI}$ in groups $\mathrm{B}, \mathrm{D}$, and $\mathrm{E}(P>0.05)$ suggesting similar transfection efficiency. HBsAg protein expression was found in groups B, D, and F. Expression was determined using a cutoff value (COV) that equal to the average absorbance value of the negative control (0.532). The absorbance of specimen $\geq$ COV indicated positive expression of HBsAg.

\section{Activation of NF-KB in $\beta 2$ GPI- and/rHBsAg-transfected cells following LPS stimulation}

A representative image of non-radioactive NF- $\kappa B$ EMSA in the six groups is shown in Figure 1 , and NF- $\kappa B$ relative quantification was represented by gray value is shown in Figure 2. Groups B, C, D, E, and F induced differential levels of activation of NF- $\kappa \mathrm{B}$, with the highest relative activity of NF- $\kappa \mathrm{B}$ observed in group D $(1404.5 \pm 11.28)$; this was significantly different compared with the other five groups $(P<0.05)$. The relative activity of NF- $\kappa \mathrm{B}$ in group $\mathrm{B}$ was $914.57 \pm 12.51$, significantly higher than levels in groups $\mathrm{A}, \mathrm{C}, \mathrm{E}$, and $\mathrm{F}$ $(P<0.05)$. The levels in group $\mathrm{E}(867.76 \pm 6.27)$ and $\mathrm{F}(882.52 \pm 7.92)$ were much higher than those of group 
$\mathrm{NF}-\kappa \mathrm{B}$ relative quantification

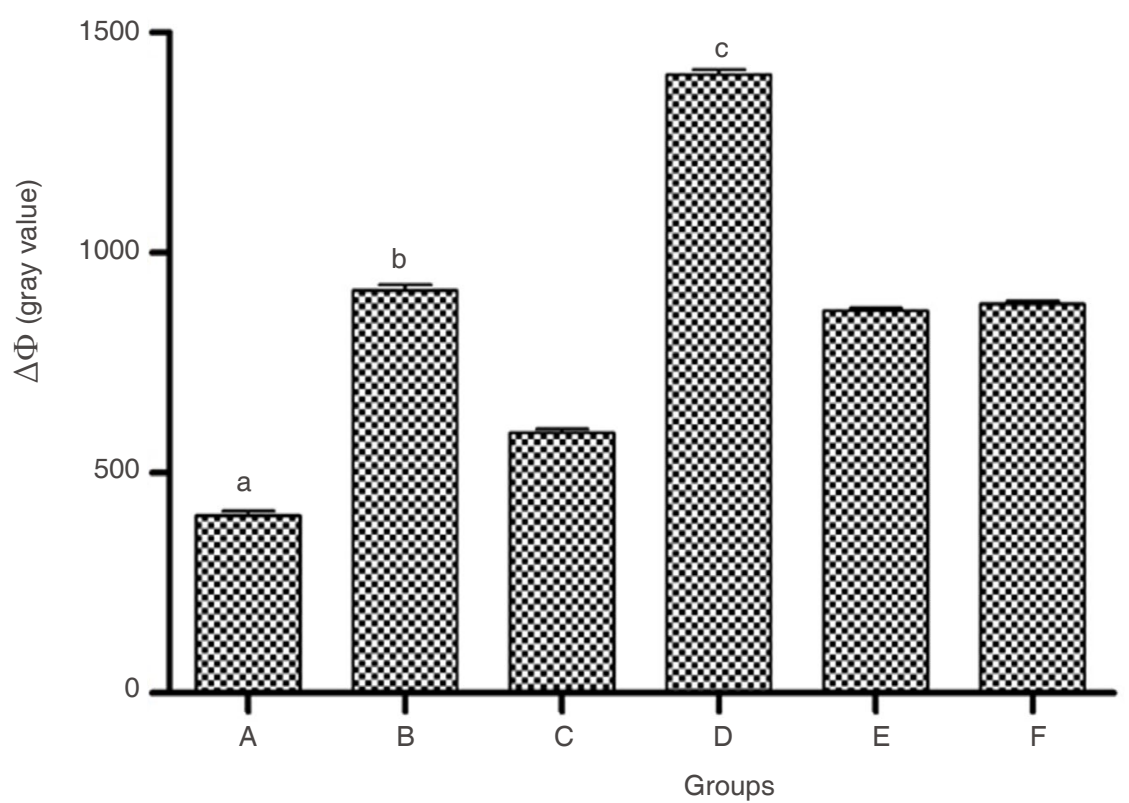

Figure 1. Detection of non-radioactive NF- $\mathrm{KB}$ by EMSA in six groups. Group $A$ : non-transfected, non-treated cells; group B: transient B2GPI-and HBsAg-transfection without LPS treatment; group C: non-transfected cells treated with $100 \mathrm{ng} / \mathrm{mL}$ LPS; group D: transient $\beta 2 \mathrm{GPI}$ - and HBsAg-transfection and treated with $100 \mathrm{ng} / \mathrm{mL}$ LPS; group E: transient $\beta 2 \mathrm{GPI}$-transfection and treated with $100 \mathrm{ng} / \mathrm{mL} \mathrm{LPS}$; group F: transient HBsAg-transfection and treated with $100 \mathrm{ng} / \mathrm{mL}$ LPS. $\beta 2 \mathrm{GPI}$ : beta2-glycoprotein I; HBsAg: hepatitis B surface antigen; LPS: lipopolysaccharide

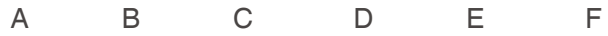

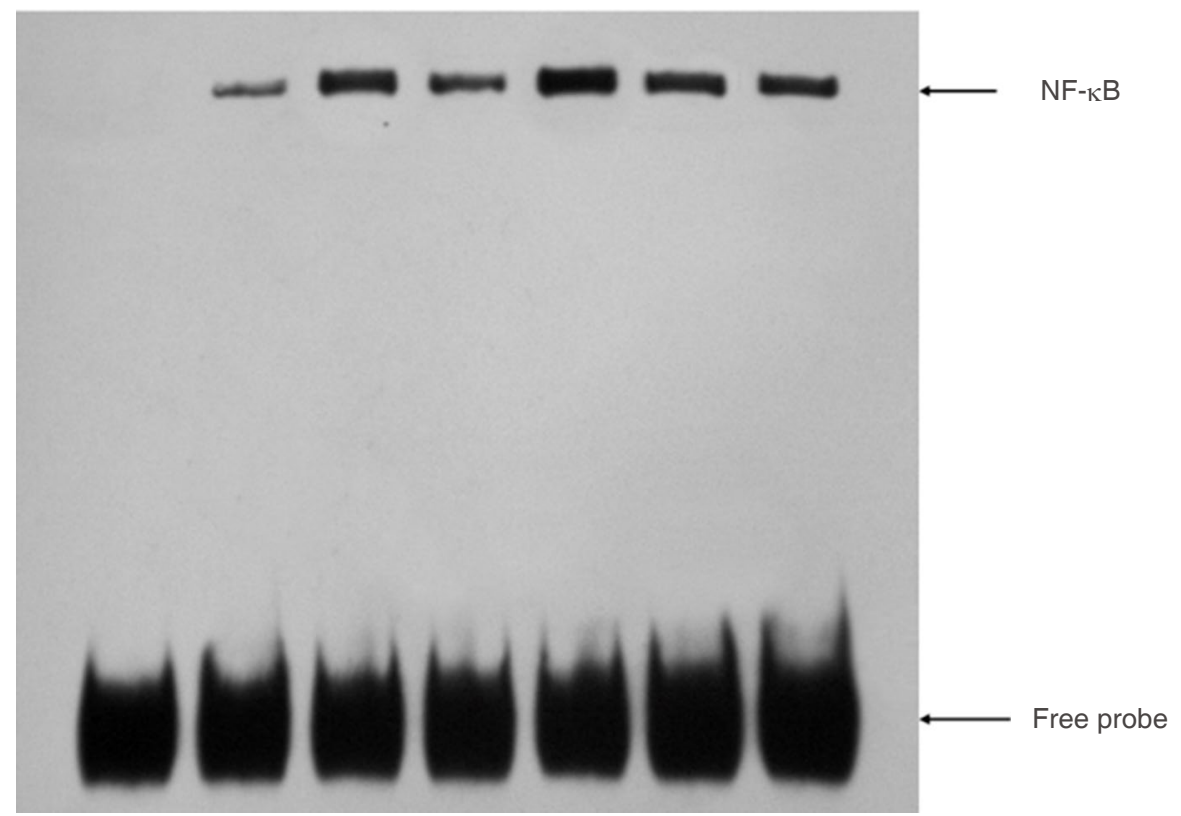

Figure 2. NF- $\kappa B$ relative quatification in six groups. Group A: non-transfected, non-treated cells; group B: transient $\beta 2 \mathrm{GPI}$-and HBsAgtransfection without LPS treatment; group C: non-transfected cells treated with $100 \mathrm{ng} / \mathrm{mL}$ LPS; group D: transient $\beta 2 \mathrm{GPI}$ - and $\mathrm{HBsAg}$ transfection and treated with $100 \mathrm{ng} / \mathrm{mL}$ LPS; group E: transient $\beta 2 \mathrm{GPI}$-transfection and treated with $100 \mathrm{ng} / \mathrm{mL}$ LPS; group F: transient $\mathrm{HBsAg}$-transfection and treated with $100 \mathrm{ng} / \mathrm{mL}$ LPS. Data presented as means $\pm \mathrm{SD}$; a: groups $\mathrm{B}, \mathrm{C}, \mathrm{D}$, E, and F compared with group A, $P<0.05$. b: group $\mathrm{B}$ compared with groups $\mathrm{A}, \mathrm{C}, \mathrm{E}$, and $\mathrm{F}, P<0.05$, c: group $\mathrm{D}$ compared with other five groups, $P<0.05$. $\beta 2 \mathrm{GPI}$ : beta2glycoprotein I; HBsAg: hepatitis B surface antigen; LPS: lipopolysaccharide 


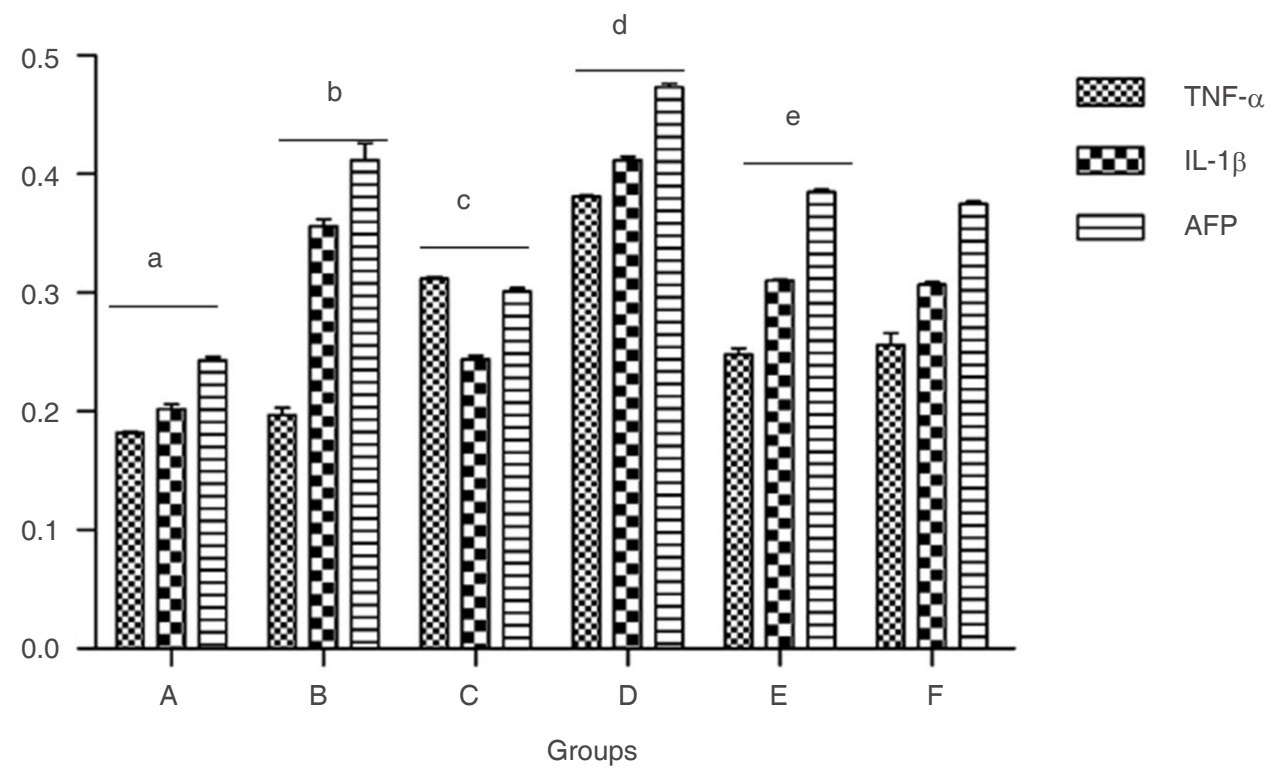

Figure 3. Expression of TNF- $\alpha, I L-1 \beta$ and AFP by ELISA in six groups. Group A: non-transfected, non-treated cells; group B: transient B2GPI-and HBsAg-transfection without LPS treatment; group C: non-transfected cells treated with $100 \mathrm{ng} / \mathrm{mL}$ LPS; group D: transient $\beta 2 \mathrm{GPI}$ - and HBsAg-transfection and treated with $100 \mathrm{ng} / \mathrm{mL}$ LPS; group E: transient $\beta 2 \mathrm{GPI}$-transfection and treated with $100 \mathrm{ng} / \mathrm{mL}$ LPS; group F: transient HBsAg-transfection and treated with $100 \mathrm{ng} / \mathrm{mL}$ LPS. Data presented as means \pm SD. a: groups B, C, D, E, and F compared with group $\mathrm{A}, P<0.05$; b: group $\mathrm{B}$ compared with groups $\mathrm{A}, \mathrm{C}, \mathrm{E}$, and $\mathrm{F}, P<0.05$; c: groups $\mathrm{E}$ and $\mathrm{F}$ compared with group $\mathrm{C}, P<$ 0.05 ; d: group $D$ compared with groups $A, B, C, E$, and $F, P<0.00$; e: group $E$ compared with group $F, P>0.05$; f: group $C$ compared with groups $B, E$, and F, $P<0.05$. $\beta 2$ GPI: beta2-glycoprotein I; HBsAg: hepatitis B surface antigen; LPS: lipopolysaccharide

$\mathrm{C}(590.4 \pm 9.49)(P<0.05)$. The level of NF-kB activation in group $\mathrm{E}$ and $\mathrm{F}$ were similar $(P>0.05)$. Taken together, these data suggest that LPS alone induced activation of NF- $\mathrm{BB}$, which enhanced by either $\beta 2 \mathrm{GPI}$ - or HBsAg-transfection. However, the highest effect was seen in doubly-transfected cells, suggesting synergism between LPS, $\beta_{2}$ GPI and HBsAg with respect to activation of NF- $\kappa B$ in HCC.

\section{LPS induced increased expression of TNF- $\alpha$, IL-1 $\beta$, and AFP in $\beta 2$ GPI- and/or HBsAg- transfected cells}

Cell supernatants from the six groups were collected and levels of TNF- $\alpha$, IL- $1 \beta$ and AFP were assayed $24 \mathrm{~h}$ after transfection of respective recombinant plasmids. As depicted in Figure 3, groups B, C, D, E, and F induced expression of TNF- $\alpha$, IL-1 $\beta$ and AFP more than did group A $(P<0.05)$. The highest expression levels of all three cytokines was seen in group D (doubly transfected with $\beta 2 \mathrm{GPI}$ and HBsAg and treated with LPS) $(P<0.001)$. The expression levels of IL-1 $\beta$ and AFP in group B was higher $(P<0.05)$ were higher than those of groups A, C, E, and F, while their expression in groups $\mathrm{E}$ and $\mathrm{F}$ were higher than those of group $\mathrm{C}$ $(P<0.05)$. The expression of TNF- $\alpha$ in group $\mathrm{C}$ was higher than that of groups $\mathrm{B}, \mathrm{E}$, and $\mathrm{F}(P<0.05)$. TNF- $\alpha$ and IL- $1 \beta$ levels were similar in groups $\mathrm{E}$ and $\mathrm{F}(P>0.05)$, while AFP in these groups were significantly higher than in group $\mathrm{A}(P<0.05)$.

\section{DISCUSSION}

HCC, one of the most common tumors, is currently the fifth most common malignant tumor worldwide, with morbidity increasing every year. Hepatitis $B$ virus (HBV) and hepatitis $\mathrm{C}$ virus (HCV) are major causes of $\mathrm{HCC}^{[10]}$. Therapeutic options include etiological treatment, resection, percutaneous ablation, trans-arterial chemoembolization (TACE), and targeted therapy. The overall efficacy of these therapies is poor, and fiveyear survival rates for early treatment of HCC are not favorable ${ }^{[11]}$. Therefore, understanding the pathogenesis of HCC (abnormal neovascularization, genomics, proteomics and signal transduction pathways) is necessary to understand how HCC occurs and to develop new therapeutic approaches. 
$\beta_{2}$ GPI is synthesized by liver cells and plays roles in anticoagulation, cell clearance, and lipid metabolism under normal physiological conditions ${ }^{[4]}$. $\beta 2$ GPI is also involved in the pathogenesis of chronic viral hepatitis, alcoholic liver disease, autoimmune liver disease, liver cirrhosis and liver cancer $^{[12]}$. A previous study showed that a fraction with maximal apoH ( $\beta 2 \mathrm{GPI})$-binding predominantly contained full Dane particles in HBV patients ${ }^{[13]}$. Gao et al. ${ }^{[14]}$ found there was a specific binding event between HBV and $\beta 2 \mathrm{GPI}$. Gao et al. ${ }^{[15,16]}$ provided the first evidence that a protein existed on SMMC-7721 cell membrane that could specifically bind $\beta_{2}$ GPI. The binding protein was later identified as annexin II. A previous study from our $\mathrm{lab}^{[6]}$, demonstrated strong $\beta_{2}$ GPI expression in hepatitis B-related HCC tissue. In addition, the combination of $\beta_{2}$ GPI and HBsAg was shown to significantly activate NF- $\kappa B$ and expression of AFP, suggesting that $\beta 2$ GPI may be involved in the pathogenesis of hepatitis B-related HCC. However, it is unknown whether $\beta 2 \mathrm{GPI}$ directly interacts with $\mathrm{HBsAg}$ or if other proteins are involved in NF- $\mathrm{KB}$ activation.

$\beta 2$ GPI is physically closed in a circular conformation, with low activity ${ }^{[17]} \cdot \beta 2$ GPI opens and adopts a J-like conformation and becomes active when combined with antibodies or anionic phospholipids. In a study ${ }^{[17]}$, it was found that LPS opened $\beta_{2} \mathrm{GPI}$, exposed its binding sites in domain V, and interacted with $\beta 2 \mathrm{GPI}$ to participate in physiology and pathology. The $\beta_{2}$ GPI and LPS complex relied on the TLR4 signaling pathway to activate NF- $\kappa B$ in macrophages. A previous study from our lab ${ }^{[9]}$ found that LPS enhanced signal transduction in $\beta 2 \mathrm{GPI}$ in liver cancer cells leading to activation of NF- $\kappa \mathrm{B}$, triggering downstream signal transduction and increasing the expression of downstream factors. This activation was related with LPS concentration. This suggests that LPS enhancement of $\beta 2$ GPI signal transduction may participate in the development of liver cancer.

LPS, a component of the cell wall of gram-negative bacteria, is an important mediator of the host inflammatory response to infection. A study of 169 patients with chronic hepatic disease found elevated levels of LPS in $27 \%, 85 \%$, and $41 \%$ of patients with chronic hepatitis, chronic hepatitis with acute exacerbation and cirrhosis, respectively ${ }^{[18]}$. In patients with chronic liver diseases, elevated levels of LPS in the portal and/or systemic circulation are common because of increases in intestinal permeability and bacterial translocation. LPS from gut microbiota contributed to HCC promotion by activating TLR4 signaling. Classically, TLR4 recognizes microbial lipids in homodimer configuration, thus activating various intracellular signaling pathways, such as the NF-kB and MAPK pathways. TLR4 has been identified in HCC and may play a role in progression of HCC. LPS-induced activation of TLR4 signaling promoted HCC cell survival and proliferation associated with regulation of the activation of the NF-kB and MAPK pathways ${ }^{[19-2]}$.

In the present study, we demonstrated substantial activity of NF-kB in cells transfected with both $\beta 2 \mathrm{GPI}$ and HBsAg and treated with LPS. Our data suggested that the combined action of $\beta 2$ GPI and HBsAg were enhanced by LPS in the progression of carcinogenesis. Constitutive expression of NF-kB is emerging as a hallmark of cancer. In fact, constitutive NF-kB activation is generally associated with cancer proliferation, survival, chemoresistance, and progression of $\mathrm{HCC}^{[23]}$.

$\mathrm{NF}-\mathrm{kB}$ is another pro-inflammatory transcription factor that triggers downstream signal transduction and increases expression of downstream factors. In the present study, inflammatory cytokines (TNF- $\alpha$, IL- $1 \beta$, and AFP) were substantially elevated in cells transfected with both $\beta 2$ GPI and HBsAg and treated with LPS, more so than by single transfections with either factor. The action of various inflammatory mediators is known to occur in carcinogenesis. TNF- $\alpha$ has been postulated to have a crucial role in the pathogenesis of various cancers. It is one of the most important pro-inflammatory cytokines involved in the growth, differentiation, cellular function and survival of many cells. It is produced by several types of cells, including macrophages, neutrophils, fibroblasts, keratinocytes, NK cells, T and B cells, and tumor cells ${ }^{[24]}$. IL-1 $\beta$ is also known to mediate several immune responses in HCV/HBV infection. There is a network of TNF- $\alpha$ and IL- $1 \beta$ secretion and interactive bio-functions in immune responses ${ }^{[24]}$. 
We found that LPS enhanced the effect of $\beta 2$ GPI- and HBsAg in development of liver cancer by increasing the activity NF- $\kappa \mathrm{B}$ and elevating levels of TNF- $\alpha$, IL- $1 \beta$, and AFP. We predict that LPS may be an initiating agent in the pathogenesis of $\mathrm{HCC}$, combining with $\beta_{2} \mathrm{GPI}$ to activate and expose $\beta_{2} \mathrm{GPI}$ binding sites to $\mathrm{HBsAg}$, in turn interacting with $\mathrm{HBsAg}$ to further modulate NF- $\mathrm{kB}$. Further studies are needed to uncover the specific mechanisms of interaction of $\beta_{2} \mathrm{GPI}, \mathrm{HBsAg}$ and LPS, and the role of $\beta_{2} \mathrm{GPI}$ in liver cancer and other hepatic diseases.

\section{DECLARATIONS}

\section{Authors' contributions}

Designed the study protocol, performed the studies and wrote the manuscript: Jing X, Ding XL

Gathered the data and performed the statistical analyses: Han NJ, Yang L, Yu YN Improved the final version of the manuscript: Tian ZB, Gao PJ

\section{Data source and availability}

The data presented is original and obtained in our laboratory. It is available with the authors and can be made available if required.

\section{Financial support and sponsorship}

This work was supported by the National Natural Science Youth Foundation of China (No. 81101853) and Natural Science Youth Foundation of Shandong Province (No. ZR2016HQ35).

\section{Conflicts of interest}

There are no conflicts of interest.

\section{Patient consent}

Not applicable.

\section{Ethics approval}

Not applicable.

\section{Copyright}

(c) The Author(s) 2018.

\section{REFERENCES}

1. El-Assaad F, Krilis SA, Giannakopoulos B. Posttranslational forms of beta 2-glycoprotein I in the pathogenesis of the antiphospholipid syndrome. Thromb J 2016;14:20.

2. Pengo VBE, Zoppellaro G, Padayattil JS, Denas G, Hoxha A, Ruffatti A, Banzato A. APS - Diagnostics and challenges for the future. Autoimmun Rev 2016;15:1031-3.

3. Meroni PL, Rovelli F, Gerosa M. Antiphospholipid syndrome in 2014: more clinical manifestations, novel pathogenic players and emerging biomarkers. Arthritis Res Ther 2014;16:209.

4. El-Assaad F, Giannakopoulos B. Posttranslational forms of beta 2-glycoprotein I in the pathogenesis of the antiphospholipid syndrome. Author Thromb J 2016;14:159-63.

5. Mehdi H, Anlar FY, Yang X, Bayer R, Sutherland K, Peeples ME. Hepatitis B virus surface antigen binds to apolipoprotein H. J Virol 1994;68:2415-24.

6. Jing X, Liu Y, Gao PJ. Beta2-GPI: a novel factor in the development of hepatocellular carcinoma. J Cancer Res Clin Oncol 2010;136:1671-80.

7. Laplante P, Subang R, Dieudé M, Levine JS, Rauch J. Interaction of $\beta 2$-glycoprotein I with lipopolysaccharide leads to Toll-like receptor 4 (TLR4)-dependent activation of macrophages. J Biol Chem 2011;286:42494-503.

8. He M, Dong Y, Wang L, Fang T, Tang W, Lv B, Chen G, Yang B, Huang P, Xia J. Pro-inflammation NF-kB signaling triggers a positive feedback via enhancing cholesterol accumulation in liver cancer cells. J Exp Clin Cancer Res 2017;36:15.

9. Jing X, Gao PJ, Han NJ, Xu YH, Zhang H, Ding XL, Wang XW, Man X, Zhang CP. Lipopolysaccharide enhances beta2-glycoprotein I activation of nuclear factor $\mathrm{\kappa B}$ in liver cancer cells. Clin Lab 2015;61:1239-45.

10. de Martel C, Maucort-Boulch D, Plummer M, Franceschi S. Worldwide relative contribution of hepatitis B and C viruses in hepatocellular 
carcinoma. Hepatology 2015;62:1190-200.

11. Dutta R. Recent advances in hepatocellular carcinoma therapy. Pharmacol Ther 2017;173:106-17.

12. Jing X, Tian ZB, Kong XJ, Ding XL. Evolving research in the relationship between beta2-glycoprotein I and liver diseases. J Genet Mol Cell Biol 2015;2:1-3.

13. Stefas I, D’Angeac AD, Morel-Baccard C, Seigneurin JM, Zarski JP, Martin M, Cerutti M, Bossy JP, Missé D, Graafland H, Veas F. Hepatitis B virus Dane particles bind to human plasma apolipoprotein H. Hepatology 2001;33:207-17.

14. Gao YH, Wang D, Shi Y, Tang TY, Piao YF, Yang HY. Studies on the association between beta-2- glycoprotein I and hepatotropis of hepatitis B virus. Chin J Hepatoma 2006;14:569-71.

15. Gao P, Wang X, Qu L, Shi Y, Yang H. A possible receptor for beta 2 glycoprotein I on the membrane of hepatoma cell line smmc 7721 . Chin Med J 2003;116:1308-11.

16. Gao PJ, Gao YH, Liu YW, Tan Y. The receptor for beta(2)GPI on membrane of hepatocellular carcinoma cell line SMMC-7721 is annexin II. World J Gastroenterol 2007;13:3364-8.

17. Agar C, Mörgelin M, Monk SD, van Os G, Levels JH, de Laat B, Urbanus RT, Herwald H, van der Poll T, Meijers JC. $\beta 2$-glycoprotein I: a novel component of innate immunity. Blood 2011;117:6939-47.

18. Roderburg C, Luedde T. The role of the gut microbiome in the development and progression of liver cirrhosis and hepatocellular carcinoma. Gut Microbes 2014;5:441-5.

19. Lin A, Zhao H, Zhang Y, Han Q, Zhang C, Tian Z, Zhang J. TLR4 signaling promotes a COX-2/PGE2/STAT3 positive feedback loop in hepatocellular carcinoma (HCC) cells. Oncoimmunology 2015;5:e1074376.

20. Wang Y, Yan W, Xiao D, Zeng Z, Ouyang Y, Huang L, Cai J, Zeng X, Chen YJ, Liu A. CXC195 suppresses proliferation and inflammatory response in LPS-induced human hepatocellular carcinoma cells via regulating TLR4-MyD88-TAK1-mediated NF-kB and MAPK pathway. Biochem Biophys Res Commun 2015;456:373.

21. Szabo G, Petrasek J, Gattu A. Gut-liver axis and sensing microbes. Dig Dis 2010;28:737-44.

22. Lai FB, Jing YY, Yu GF, Han ZP, Yang X, Zeng JX, Zhang HJ, Shi RY, Li XY, Pan XR, Li R, Zhao QD, Wu MC, Zhang P, Liu JF, Wei LX. Lipopolysaccharide supports maintaining the stemness of CD133(+) hepatoma cells through activation of the NF-kB/HIF-1 $\alpha$ pathway. Cancer Letters 2016;378:131-41.

23. Dolcet X, Pallares J, Matias-Guiu X. NF-kB in development and progression of human cancer. Virchows Arch 2005;446:475-82.

24. Yu Yang, Feng R, Sheng Bi. The TNF- $\alpha$, IL-1B and IL-10 polymorphisms and risk for hepatocellular carcinoma: a meta-analysis. $J$ Cancer Res Clin Oncol 2011;137:947-52. 